\title{
ОЖИДАНИЕ РЕБЕНКА ВО ВРЕМЯ ПАНДЕМИИ: ВЛИЯНИЕ СТРЕССОГЕННЫХ ФАКТОРОВ НА ПРЕНАТАЛЬНЫЙ СТРЕСС ПАРТНЕРОВ И СПОСОБЫ СОВЛАДАНИЯ С НИМ
}

Исследование поддержано Министерством высшего образования и науки FZEW-2020-0005

Одинцова О.Ю. (Ярославский государственный медицинский университет,

Ярославль, Россия) odintcova@ysmu.ru Крюкова Т.Л. (Костромской государственный университет, Кострома, Россия) tat.krukova44@gmail.com 乙tinluјugर्ume uर्u. 31.07.2021

9pmpunuर्जuध mर्जu. 26.08.2021

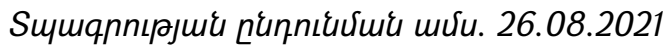

Ожидание ребенка является стрессовым жизненным периодом, поскольку детерминирует ряд изменений на организменном, личностном, социальном и социокультурном уровне как у женщин, так у партнеровмужчин. Подобное состояние обозначается как "пренатальный стресс», источником которого выступают разноуровневые стрессоры специфические для периода ожидания ребенка (детерминированные протеканием и спецификой беременности), индивидуальные (личностно обусловленные) и макросоциальные. Текущая эпидемиологическая ситуация потенциально увеличивает вероятность развития пренатального стресса, сопряженного со стойкой афрфективной симптоматикой, тревожной, депрессивной или фобической. Данная работа сконцентрирована на изучении страхов как проявлении пренатального стресса, поскольку именно страх, различный по содержанию, является характерной чертой нашей реальности. Вынужденный карантин и боязнь инфицирования в сочетании с ограниченным доступом к профессиональной медицинской и социальной поддержке усиливает интенсивность переживаний в парах, готовящихся к родительству. Для углубленного изучения многокомпонентных стрессоров, возникающих во время беременности и способов совладания с ними, реализовано эмпирическое исследование в диадах, ожидающих ребенка (n=203). Результаты свидетельствуют, что партнеры практически в равной степени уязвимы по отношению к стрессорам, но вариации совладания с ними у женщин и мужчин различны. Женщины демонстрируют большую гибкость в использовании совладающего поведения, у мужчин очевидна тенденция отстраниться от обстоятельств. Однако в вопросах беременности, родов и 
здоровья наблюдаются конструктивные способы совладания. Выводы свидетельствуют о необходимости разработки конкретных мероприятий, ориентированных не только на женщин, но и на мужчин.

Ключевые слова: стрессоры, пренатальный стресс, женщины, мужчины, беременность, совладание.

DOI: https://doi.org/10.46991/SBMP/2021.4.2.242

Пандемия COVID-19 затронула все сфреры жизни социума и отдельного субъекта. Научное сообщество быстро отреагировало на новые обстоятельства: практически во всех странах мира растет количество исследований, посвященных влиянию пандемии на население. В частности, сообщается об увеличении признаков стресса - тревожности, депрессии, фобий - особенно среди женщин и субъектов без пары (одиноких) [1] Ограничительные меры, принимаемые для предотвращения распространения коронавирусной инфекции, могут рассматриваться как дополнительные стрессоры и для будущих родителей, чья уязвимость потенциально повышается. Скандинавские коллеги предупреждают, что относительный риск по показателям материнской смертности для беременных женщин выше по сравнению с небеременными респондентками аналогичного возраста $(n=50)$. Авторы заключают, что результаты основаны на небольшой выборке, однако они достаточно тревожны, чтобы их игнорировать [4]. Не менее опасна заболеваемость плода. В метаобзоре зарубежных данных отмечается, что для 92\% женщин $(n=108)$ с подтвержденной ковидной инфекцией применялось хирургическое родоразрешение по причине внутриутробного дистресса ребенка. В выборке также зафиксированы 2 летальных исхода - внутриутробный и неонатальный. Исследователи констатируют, что в литературе по-прежнему отсутствует общепризнанный взгляд относительно влияния COVID-19 на мать и ребенка, но вероятность неблагополучного течения заболевания и осложнений, сопряженных с материнской и младенческой смертностью, преждевременными родами, выкидышами достаточно велика [5]. Противоречивая и явно недостаточная информация повышает волнение и страхи будущей матери. Помимо переживаний за свою жизнь, жизнь ребенка и близких, беременных женщин пугает вынужденная трансорормация в системе медицинского наблюдения и практики: реорганизация медицинских учреждений, ограничения в получении узкоспециализированной помощи, изменение плана родов, запрет на поддержку супруга или доулы во время родоразрешения и т.д. [2]. Добавим, что вместе с опасениями, связанными с беременностью, семья, ожидающая ребенка, во время пандемии испытывает те же трудности, что и общество в целом - ухудшение фринансового положения, социальная изоляция, напряжение в отношениях с партнером, эмоциональное неблагополучие [1]. Совокупность 
всех этих многообразных стрессоров можно разделить на три группы: (а) специфические для беременности стрессоры, среди которых доминирующим является страх, связанный с инфицированием COVID-19 и его последствиями; (б) индивидуальные стрессоры, обусловленные социальной микросредой субъекта (прежде всего, семейной); (в) социальные макрострессоры (экономические и социально-политические последствия эпидемии) [3].

Комплексное сочетание разноуровневых стрессоров провоцирует состояние продолжительного пренатального стресса - комплекса негативных эмоционально-когнитивных переживаний субъекта, возникающих во время ожидания ребёнка, проявляющихся в усилении отрицательной аффеккивной симптоматики - тревоги, депрессии, страха. Стоит отметить, что некоторые аспекты переживаний пренатального стресса у мужчин раскрыты в работах, посвященных психологической готовности к отцовству, но их численность и разнообразие по-прежнему уступают трудам в области психологии материнства.

Дизайн исследования. Целью работы является изучение совладающего поведения женщин и мужчин, ожидающих появления ребенка, со стрессорами в условиях пандемии.

Гипотезы 1. В период беременности пандемия провоцирует особое аффрективное состояние, выраженное у женщин и мужчин в одинаковой степени - страх перед коронавирусом. 2 Пренатальный стресс является состоянием, характерным для обоих партнеров. 3. Женщины используют более вариативный репертуар копингов для совладания со стрессорами.

Выборка. Исследование проводилось с ноября 2020 по март 2021 года. Выборка составила 101 диаду ( $=203)$, ожидающую ребенка: 102 женщины от 21 до 40 лет $(m=30,96$ лет, $S D=4,79)$ (в анализе участвовал один бланк женщины, заполненный без партнера), 101 мужчина от 19 до 52 лет (m=33,06 лет, $\mathrm{SD}=5,74)$. Из них 75\% состояли в браке, 24\% - в «гражданском» браке (разг.). Стаж семейной жизни - 6,4 года. Срок беременности - в пределах III триместра $(\mathrm{m}=31,28$ недель). Партнеры ожидали преимущественно второго ребенка $(m=2,52)$. Об осложнениях беременности сообщили $25 \%$ женщин.

Метод. Исследование сопровождалось авторской анкетой, выявляющей обобщенные сведения о супружеских / партнерских отношениях и особенностях протекания беременности. Основной инструментарий составили: 1). «Шкала страха COVID-19» (Griffiths, Pakpour et al.., 2020). Коэффрициента $\alpha$-Кронбаха продемонстрировал хороший результат ( $\alpha=0,87) ; 2)$. «Шкала воспринимаемого стресса-10» (Cohen et al., 1983) в адаптации В.А. Абабкова и др., 2016; 3). «Опросник пренатального дистресса» (Ibrahim, Lobel, 2020). Инструментарий состоит из 18 вопросов. Смысловое содержание методики концентрируется на тематике страхов беременности и родов. Согласие с утверждениями оценивается с помощью по 3-балльной шкалы Лайкерта. Коэфффициент $\alpha-$ 
Кронбаха составил $\alpha=0,83$. 4). «Опросник способов совладания» (Лазарус, Фолкман, 1988) в адаптации Т.Л. Крюковой, Е.В. Куфттяк, М.С. Замышляевой, 2004. Для статистической обработки применены дескриптивный, сравнительный и корреляционный анализ. Обработка данных производилась при помощи компьютерного статистического пакета программ (SPSS-22).

Результаты. Результаты исследования переживаний, связанных с пандемией, свидетельствуют о том, что у женщин страх COVID-19 выражен выше, чем у мужчин ( $m=15,24, S D=5,26)$. Напряженность беременных женщин текущей эпидемиологической обстановкой можно характеризовать как среднюю. У мужчин подобные переживания также присутствуют, однако их уровень ниже, чем у женщин ( $m=12,48, S D=5,03)$. Следовательно, мужчины проявляют невысокую озадаченность по поводу ситуации пандемии (34\% от максимально возможного, что является ниже среднего). Специфический стресс во время ожидания ребенка оценивался по показателям "Опросника пренатального дистресса». Обнаружено, что у женщин и мужчин цифровые значения практически идентичны (у женщин-m=13,05, $\mathrm{SD}=6,44$, у мужчин$\mathrm{m}=13,28, \mathrm{SD}=5,91)$. Это означает, что мужчины, также, как и женщины, в равной степени ощущают пренатальный стресс, а его выраженность соответствует $39 \%$ от максимально возможного. Вместе со стрессом, обусловленным беременностью на фоне пандемии, партнеры могут испытывать иные виды стрессоров. Для интеграции данных показателей была использована «Шкала воспринимаемого стресса». Выявлено, что женщины ( $\mathrm{m}=24,49, \mathrm{SD}=5,59)$ более чувствительны к многообразным стресс-фракторам, чем мужчины ( $m=22,46, \mathrm{SD}=6,11)$. В течение последнего месяца они ощущают перенапряжение $(m=15,17, \quad S D=4,56$, при норме $m=13,62)$, при этом противодействие стрессу имеют равную невысокую выраженность как в женской, так и в мужской выборке. Иными словами, женщины переживают напряжение, которое не отмечается у мужчин, при этом обе группы респондентов демонстрируют недостаточный уровень индивидуальных усилий (по шкале «Противодействие стрессу») для преодоления ситуации. С целью проверки статистической значимости различий между мужчинами и женщинами по описанным стрессорам применен Т-критерий Вилкоксона (рис. 1). 


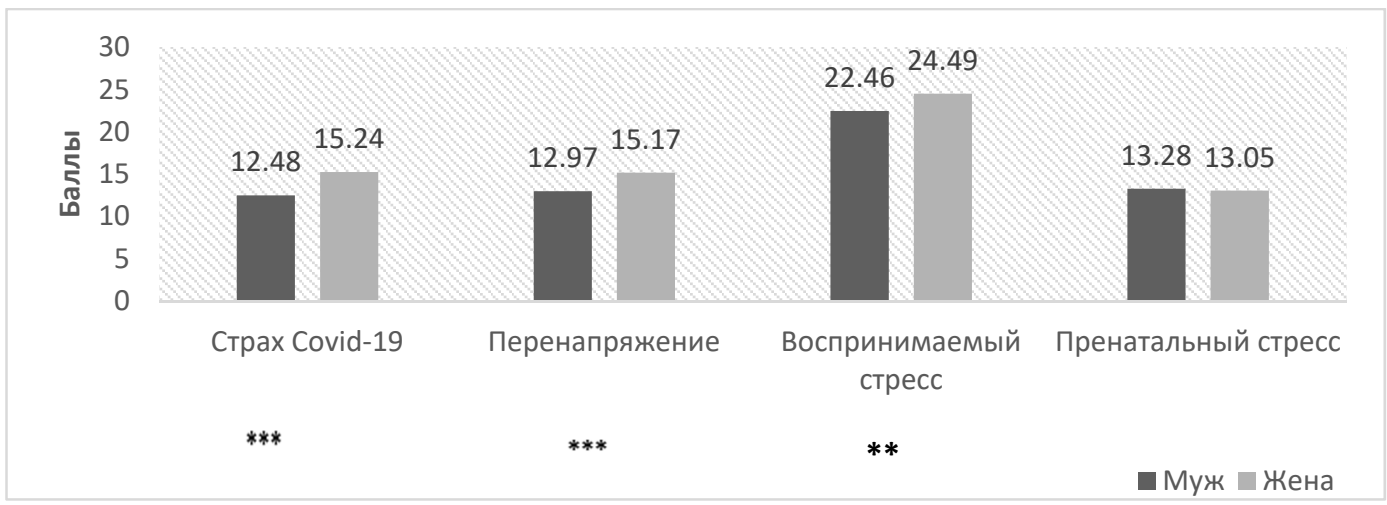

** - различия на уровне значимости $\mathrm{p}<0,01$

*** - различия на уровне значимости $\mathrm{p}<0,001$

Рис. 1. Различия в переживании стрессоров мужчинами и женщинами (T-критерий) (женщины n1 =102; мужчины n2=101).

Для совладания с многообразными стрессорами партнеры прибегают к определенным копинг-стратегиям. Так, например, у женщин положительная переоценка ( $m=11,29, \mathrm{SD}=4,87)$, социальная поддержка $(\mathrm{m}=9,89, \mathrm{SD}=3,97)$ и бегство-избегание $(\mathrm{m}=8,81, \mathrm{SD}=4,55)$ являются наиболее часто применяемыми стратегиями. Показатели этих шкал соответствуют средним нормативным значениям. Показатели мужских индивидуальных копингов выражены только на уровне низких тестовых норм. Интересно, что и женщины, и мужчины в меньшей степени используют стратегию принятия ответственности.

Рассмотрим особенности структурных взаимосвязей, полученных этим шкалам в женской выборке: Уровень воспринимаемого стресса тесно и положительно связан с большей частью индивидуальных копингов: конфрронтацией, дистанцированием, принятием ответственности и избеганиембегством, самоконтролем ( $p<0,01)$. Соответственно, чем выше уровень стресса, тем интенсивнее и вариативнее женщины используют различные способы совладания. Также можно отметить более тесные связи показателя воспринимаемого стресса с общими особенностями жизненного контекста: наличием осложнений беременности, официальностью брака, совместным проживанием. Собственно, беременность предполагает ориентацию на некие «исходные» аспекты текущих обстоятельств, поскольку женщина в положении от них зависима в большей степени, чем мужчина. Показатели же пренатального дистресса тесно положительно взаимосвязаны с напряженностью всех индивидуальных копингов женщины. В мужской выборке показатель воспринимаемого стресса тесно и положительно коррелирует с индивидуальными копингами по типу конфронтации ( $r s=0,33$; $p<0,001)$, дистанцирования ( $r s=$ $0,32 ; p<0,001)$, бегства ( $r s=0,35 ; p<0,001)$ и принятия ответственности 
( $r s=0,25 ; p<0,01)$. Соответственно, чем выше уровень воспринимаемого мужчинами стресса, тем более напряженными становятся дезадаптивные стратегии совладания мужчин в сочетании с признанием собственной роли в сложившихся обстоятельствах. Показатель пренатального дистресса у мужчин также достаточно тесно взаимосвязан с копингами: выявлены прямые корреляционные связи с конфронтацией ( $r s=0,27 ; p<0,01)$, дистанцированием ( $r s=0,25 ; p<0,01)$, самоконтролем ( $r s=0,29 ; p<0,01)$, поиском социальной поддержки ( $r s=0,30 ; p<0,01)$, бегство-избегание $(r s=0,28 ; p<0,01)$ и принятие ответственности ( $r s=0,23 ; p<0,05)$. Таким образом, пренатальный дистресс, в отличие от воспринимаемого стресса, более тесно связан с различными индивидуальными копингами мужчин.

Обсуждение. В период ожидания ребенка женщины испытывают большее состояние напряженности, обусловленное разнообразными стрессорами - специфическими, индивидуальными и макросоциальными, чем их партнеры-мужчины. Это объясняется спецификой беременности как общего (диадического) стрессора: он несимметричен для партнеров. Женщину он затрагивает напрямую, поскольку связан с ее организмом, а мужчину косвенно, через переживания партнерши. Вероятно, чем более интимные, близкие, позитивно насыщенные отношения партнеров, тем в большей степени женщина вербально или невербально транслирует свое состояние стресса партнеру, вовлекая его в совместное переживания. Введение в исследование методик, посвященных супружеским / партнерским отношениям, позволило бы высказываться в этом вопросе более определенно.

Очевидно, во время беременности женщина более уязвима, напряжена и стресс-реактивна, чем мужчина, что отражается в полученных результатах. Тем не менее, специфический для беременности стресс (в терминологии используемого инструментария - пренатальный дистресс) в равной степени испытывают оба партнера. Эти результаты позволяют предположить, что пренатальный стресс, проявляющийся в разнообразии аффективных состояний, является универсальным нормативным переживанием для обоих партнеров, который тесно сопряжен с особенностями индивидуального копинга. Исходя из результатов, можно говорить о специфике совладающего поведения женщин и мужчин ответ на действие стрессоров в период ожидания ребенка. У женщин отмечается напряженность всех копинг-ресурсов в ответ на воспринимаемый стресс и пренатальный дистресс. Для снижения напряженности и восстановления психологического благополучия женщины прибегают ко всем возможным стратегиям, демонстрируя максимально возможный репертуар совладающего поведения. При этом, нет ни одной корреляционный связи женских копингов со шкалой страха COVID-19, хотя эти переживания характеризуются средней степенью выраженности. (K слову, полученные данные соответствуют 
результатам петербургских коллег, выявивших у подавляющего большинства респонденток в положении $(\mathrm{n}=83)$ умеренный (у $37 \%$ испытуемых) и легкий (у 38\%) уровень стресса (Блох, 2020)). Возможно, утверждения шкалы сформулированы прямолинейно (к примеру, «Я боюсь умереть от COVID-19») и вызывают внутреннее сопротивление. С другой стороны, ситуация пандемии может детерминировать не только конкретизированные страхи (инфицирования или летального исхода), но и недиффреренцированное общее напряжение и тревогу. В этом случае шкалы другого опросника более чувствительны к ним. У мужчин общий психологический смысл выявленных взаимосвязей стресса и копинга состоит в том, что их стрессовые переживания связаны с усилением интенсивности ряда индивидуальных копингов, преимущественно неконструктивных, отражающих попытки «отодвинуться» от имеющихся жизненных обстоятельств. Стоит подчеркнуть, что наблюдается взаимосвязь пренатального дистресса мужчин с конструктивными копингами. Напомним, что содержательно «Опросник пренатального дистресса» сосредоточен только на одном специфическом для периода ожидания ребенка стрессоре - страхе беременности и родов. Вероятно, эти переживания более глубинные, затрагивающие психологические, личностные и социокультурные аспекты функционирования мужчины. Следовательно, от них трудно отстраниться (как и от будущего ребенка), возникает необходимость эти переживания «проработать» конструктивными видами совладания. Представляется также важным отметить тот фракт, что пренатальный дистресс мужчин, в отличие от показателя воспринимаемого стресса, связан с наличием осложнений беременности. Страх COVID-19 в мужской выборке провоцирует поведение по типу конфронтации и принятия ответственности. Действительно, находясь в отпуске по беременности, женщина невольно сокращает круг социального взаимодействия иногда настолько сильно, что он ограничивается только супружеским общением. Мужчина понимает меру своей ответственности в период эпидемии.

Подводя итоги, сделаем следующие выводы: 1) Мужчины, как и женщины, в равной степени (зеркально) испытывают пренатальный стресс, однако, женщины более чувствительны в отношении стресс-фракторов; 2) В ответ на действие стрессоров женщины используют все формы совладания, демонстрируя гибкость применяемых стратегий. Мужские копинги зависят от стрессора: в случае житейских обстоятельств они имеют тенденцию к уклонению от текущей ситуации, в вопросах, концентрирующихся вокруг тематики беременности, родов и эпидемиологической ситуации наблюдаются конструктивные способы совладания. 3). Страх перед коронавирусом выражен у женщин, вместе с тем, в этой группе не фиксируются стратегии совладания с ним, у мужчин страх несколько ниже, а применяемыми копингами являются конфронтация и принятие ответственности. 


\section{Литература}

1. Крюкова Т.Л. Стресс и совладание в семье в период самоизоляции во время пандемии COVID-19/T.Л. Крюкова, О.А. Екимчик, Т.П. Опекина, Н.С. Шипова//Социальная психология и общество, 2020, Том 11.-№4.c. 120-134.

DOI: https://doi.org/10.17759/sps.2020110409.

2. Kahyaoglu S.H. Anxiety, depression, and related factors in pregnant women during the COVID-19 pandemic in Turkey: A web-based crosssectional study / S.H. Kahyaoglu, B. Kucukkaya // Perspectives in psychiatric care. - 2020. - Vol. 10. DOI: 1111/ppc.12627.

3. Preis H. Psychometric properties of the Pandemic-Related Pregnancy Stress Scale (PREPS) / H. Preis, B. Mahaffey, M. Lobel// Journal of Psychosomatic Obstetrics and Gynecology. - 2020. - Vol. 41. - Iss. 4. - pp. 191-197. DOI: 10.1080/0167482X.2020.1801625.

4. Westgren M. Severe maternal morbidity and mortality associated with COVID-19: The risk should not be downplayed / M. Westgren, K. Pettersson, H. Hagberg, G. Acharya // Acta Obstetricia et Gynecologica Scandinavica. - 2020. - Vol. 99. - Iss. 4. pp. 815816. DOI:10.1111/aogs.13900.

5. Zaigham M. Maternal and perinatal outcomes with COVID-19: A systematic review of 108 pregnancies / M. Zaigham, O. Andersson // Acta Obstetricia et Gynecologica Scandinavica. - 2020. - Vol. 99. - Iss. 4. - pp. 823- 829. DOI:10.1111/aogs.13867.

\section{EXPECTATION OF A CHILD DURING A PANDEMIC: THE INFLUENCE OF STRESS FACTORS ON THE PRENATAL STRESS OF PARTNERS AND METHODS OF COLLATING IT}

Research supported by the Ministry of Higher Education and Science FZEW2020-0005

Odintsova O.Yu. (Yaroslavl State Medical University, Yaroslavl, Russia) Kryukova T.L. (Kostroma State University, Kostroma, Russia)

Expectation of a child is a stressful life period, since it determines a number of changes at the organismic, personal, social and sociocultural level in both women and male partners. This condition is referred to as "prenatal stress", the source of which are stressors of different levels - specific for the period of expectation of the child (determined by the course and the specifics of pregnancy), individual (personality-related) and macrosocial. The current epidemiological situation potentially increases the likelihood of developing prenatal stress associated with 
persistent affective symptoms - anxious, depressive or phobic. This work is focused on the study of fears as a manifestation of prenatal stress, since it is fear, different in content, that is a characteristic feature of our reality. Forced quarantine and fear of infection, combined with limited access to professional medical and social support, heightens the intensity of the experience in couples preparing for parenthood. For an in-depth study of multicomponent stressors that arise during pregnancy and ways of coping with them, an empirical study was carried out in dyads awaiting a child $(n=203)$. The results indicate that partners are almost equally vulnerable to stressors, but the variations in coping with them are different for women and men. Women show great flexibility in using coping behavior; men have a clear tendency to distance themselves from circumstances. However, in matters of pregnancy, childbirth and health, there are constructive coping methods. The findings indicate the need to develop specific measures aimed not only at women, but also at men.

Keywords: stressors, prenatal stress, women, men, pregnancy, coping. 